\title{
RELEVANSI MAZMUR 119: 97-106 DALAM MEMBANGUN KECINTAAN TERHADAP TAURAT TUHAN
}

\author{
Oleh : Ferdinan Pasaribu, S.Th \\ Afiliasi : Prodi Teologi, STT Ebenhaezer Tanjung Enim \\ Email : ferdinanmarcos1994@gmail.com
}

\begin{abstract}
:
A person who understands the significance of God's word will certainly love His laws as well as King David. Because the word of God always gives directions for King David's life. The love of the Law of God gave birth to a commitment for him to meditate on all day long. The significance of God's word is: First, the Giver of the word is Almighty God. Second, God's Word contains all the rules of life for all humans. Third, God's Word provides an intimacy between people and God. Fourth, the word of God can shape the character of life. That significance makes King David love the word of God. But, in fact, today there are many Christians who do not understand the significance of God's word so that Christians do not have the desire to love and meditate on the word of God. This condition is found in the Protestant Gospel Archipelago Church of Karang Anyar Lampung where the congregation does not yet understand the significance of God's word so that the congregation does not have a love of God's word. The church does not yet understand that the giver of the word is Almighty God. The church does not understand that the word of God reveals all the rules of life, intimacy and can shape character. Therefore, the church must understand the significance of God's word. If the church understands the significance of God's word, the church will love His words and keep all His laws.
\end{abstract}

\begin{abstract}
Abstrak :
Seorang yang memahami signifikansi firman Tuhan tentu akan mencintai hukum-hukum-Nya seperti halnya raja Daud. Sebab firman Tuhan senantiasa memberikan petunjuk hidup bagi raja Daud. Kecintaan terhadap Taurat Allah melahirkan sebuah komitmen baginya untuk merenungkannya sepanjang hari. Signifikansi firman Tuhan ialah: Pertama, Pemberi firman adalah Allah yang Mahakuasa. Kedua, Firman Tuhan memuat segala aturan hidup bagi semua manusia. Ketiga, Firman Tuhan memberikan intimasi antara umat dan Allah. Keempat, firman Tuhan dapat membentuk karakter hidup. Signifikansi tersebutlah yang membuat raja Daud mencintai firman Tuhan.Akan tetapi, pada kenyataannya saat iniada banyak orang Kristen belum memahami signifikansi firman Tuhan, sehingga membuat orang Kristen tidak memiliki hasrat untuk mencintai dan merenungkan firman Tuhan. Kondisi ini didapati di Gereja Protestan Injil Nusantara Karang Anyar Lampung dimana jemaat belum memahami signifikansi firman Tuhan sehingga jemaat tidak memiliki kecintaan terhadap firman Tuhan. Jemaat belumlah memahami bahwa pemberi firman adalah Allah yang Mahakuasa. Jemaat belum memahami bahwa firman Tuhan menyatakan segala aturan hidup, sebuah intimasi dan dapat membentuk karakter. Oleh karena itu, jemaat haruslah memahami signifikansi firman Tuhan. Jika jemaat memahami signifikansi firman Tuhan, maka jemaat akan mencintai firman-Nya dan memelihara segala hukum-hukum-Nya.
\end{abstract}

Kata Kunci : Relevansi, Mazmur, Kecintaan, Taurat

Metode : 
Dalam penulisan karya ilmiah ini, penulis menggunakan metode deskriptif-bibliologis, dengan menggunakan prinsip-prinsip hermeneutika agar dapat menemukan maksud dan makna dalam teks yang relevan dengan konteks saat ini. Penulis menggunakan metode tersebut oleh karena metode tersebut di dalam penyelesaiannya sesuai dengan permasalahan yang akan penulis teliti.

\section{Pendahuluan}

Alkitab adalah firman Allah menyajikan banyak nasihat dan petunjuk yang sangat berguna dan mengandung janji yang Agung. Semua bagian dalam kitab suci itu selalu menawan untuk dibaca. Namun Alkitab tidak akan memberikan nasihat jika tidak dibaca, direnungkan, dicintai serta melakukannya dengan penuh ketaatan. Josh Mc Dowell menuliskan "Alkitab menyediakan semua hal yang patut diketahui seseorang dan memberitahukan kepadanya bagaimana menyenangkan hati Allah."1

W. F. Albright menuliskan:

Isi Alkitab jauh melaumpaui semua kepustakaan agama dan memberikan hikmat kepada orang-orang di segala tempat dan sepanjang waktu. Alkitab itu istimewa, unik, tidak ada buku lain yang dapat menandinginya. Inggris mempunyai dua buku, Alkitab dan Shakespeare. Inggris menjadikan Shakespeare sukses, tetapi Alkitab yang adalah firman Tuhan telah menjadikan Inggris sukses. ${ }^{2}$

Firman Tuhan merupakan dasar bagi semua orang yang hendak bertumbuh dalam Tuhan, berakal budi, berhikmat, bijaksana, dapat menguasai diri, setia kepada kebenaran. Cinta kepada firman Tuhan adalah dasar yang membuat seseorang tetap berpegang, memelihara, dan melaksanakan Taurat Tuhan dalam segala keadaan bahkan juga menghadirkan rasa suka, kemauan, dan kerinduan untuk melakukannya.

Alkitab memberikan fakta bahwa hanya ada satu jenis pendidikan yang dapat mengubah manusia berdosa menjadi manusia yang beradab dan bermoral, bijaksana, berakal budi, berhikmat, dewasa, dapat mengendalikan diri, memahami tujuan Allah, yaitu pendidikan yang bersumber dari Allah melalui firman-Nya. Dengan merenungkan firman Tuhan kerohanian dikuatkan dan menyadari tuntunan Tuhan dalam hidup serta dapat membantu manusia untuk melangkah berdasarkan kehendak-Nya.

\section{HASIL DAN PEMBAHASAN}

\section{Hakikat Signifikansi Firman Tuhan}

\footnotetext{
${ }^{2}$ Josh Mc Dowell dan Don Stewart, Jawaban bagi pertanyaan orang yang belum percaya, (Malang: Gandum Mas, th), 13
} 
Signifikansi firman Tuhan menurut Mazmur 119: 97-106 ialah memberikan kebijaksanaan, akal budi, pengertian, mampu menguasai diri, setia melakukan kebenaran Allah, membenci dosa, cinta kepada kebenaran. Dengan jemaat memahami signifikansi firman Tuhan hal tersebutakan menolong jemaat memiliki komitmen dan kerinduan untuk merenungkan firman Tuhan dan melakukan kebenaran firman Tuhan. Maka menurut hemat penulis upaya yang perlu dilakukan oleh gereja untuk membawa jemaat kepada sebuah pemahaman dalam memahami signifikansi firman Tuhan ialah perlunya pembinaan melalui ibadah kategorial. Ibadah kategorial adalah sebuah kegiatan ibadah yang mempelajari firman Tuhan secara teliti yang akan memberikan pemahaman bagi jemaat. Ibadah kategorial akan sangat menolong jemaat di dalam memahami hakikat signifikansi firman Tuhan.

Kata "perintah-Mu" dalam Bahasa Ibrani מצוּוֹ (misewot) commandments ditulis

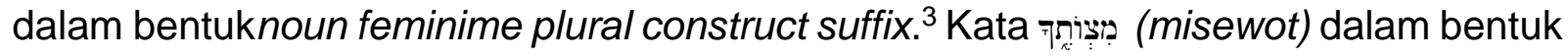
construct merupakan sebuah tindakan yang dilakukan dengan sungguh-sungguh. Suffix merupakan kata penunjuk yang menunjuk kepada Allah sebagai pemberi perintah dan pemilik firman. Dalam NIV memakai kata commands ${ }^{4}$ dalam NASB memakai kata commandsments. ${ }^{5}$ Dalam TWOT kata (misewot) memiliki pengertian (judgment, govern, justice hukum, custom, manner. Dalam konteks orang Yahudi istilah perintah-Mu digunakan untuk instruksi seorang ayah kepada seorang anak. ${ }^{6} \quad K a t a$ "perintah-Mu" menggambarkan sebuah instruksi, kemudian menggambarkan pemenuhan perintah Allah Israel. ${ }^{7}$ Tuhan menjamin kebenaran firman-Nya dengan perintah-Nya. ${ }^{8}$ Istilah govern sendiri menjelaskan sebuah kekuasaan yang memerintah secara keseluruhan. ${ }^{9}$ Sehingga kata perintah-Mu mengacu kepada peraturan dan ketetapan yang mengungkapkan peraturan Allah yang berkuasa atas kehidupan yang patut ditaati. Perintah Allah mengandung janji dan otoritas dari semua perintah. Perintah Tuhan adalah dasar kehidupan yang mengandung isi hati Allah dan mengingatkan hidup semua umat Allah. Di dalam perintah Tuhan tersirat semua peraturan dan ketetapan-ketetapan Allah. Maka, makna kata perintah-Mu merupakan ungkapan sebuah keseluruhan aturan dasar hidup sebagai umat Allah.

\section{Pemberi Firman Adalah Allah Yang Mahakuasa}

\footnotetext{
${ }^{3}$ John Joseph Owens, Analytical Key to the Old Testament Vol 3 Ezra-Song Og Salomon, 480

${ }^{4}$ Kenneth Barker, The NIV Study Bible New International Version, 919

${ }^{5}$ Lockman Foudation, New American Standard Bible, (Califirnia: J. B. McCabe Company,1977), 875

${ }^{6}$ R. Laird Harris, Gleason L. Archer and Bruce K. Waltke, Theological Wordbook Of The Old Testament, (Chicago: The Moody Bible Institute, 1980), 948

${ }^{7}$ Keluaran 25-30; Keluaran 36-39; Imamat 8

${ }^{8}$ Tuhan akan memerintahkan berkat bagi mereka yang setia kepada perintah-Nya.Mazmur 105: 8; 111: 9; Mazmur 133: 3; Ulangan 28:

${ }^{9}$ Jhon M. Echols dan Hassan Shadily, Kamus Inggris-Indonesia, (Jakarta: PT Gramedia, 1982), 276
} 
Alkitab adalah Firman Allah, pernyataan ini adalah prinsip dasar kaum Injili. ${ }^{10}$ Alkitab berperan sebagai penyingkapan diri Allah (God's self-disclosure). ${ }^{11}$ Firman Tuhan sungguh berkuasa. Oleh firman, Allah menciptakan alam semesta.Oleh firmanNya, Allah menopang segala yang ada. ${ }^{12}$ Dalam konteks raja Daud Allah berkuasa atas segala keadaan.

Jika jemaat memahami bahwa pemberi firman adalah Allah yang Mahakuasa dan pemilik segala sesuatu mereka pasti akan dapat mencintai firman Tuhan. Ketika jemaat memahami akal hal tersebut, jemaat tidak akan hidup di dalam kekuatiran atau putus asa. Oleh karena itu jemaat haruslah memahami dengan baik bahwa pemberi firman adalah Allah yang berkuasa atas segalanya, berkuasa memelihara kehidupan dan memberi keselamatan. Maka dalam bagian ini jemaat perlu memahami beberapa hal, diantaranya:

\section{Allah Memelihara Kehidupan}

Daud sangat meyakini bahwa janji Allah memberikan sebuah kenikmatan hidup yang membuatnya senantiasa berharapkepada Allah. Janji Allah mampu menolong manusia untuk tetap teguh. Alasan mendasar mengapa firman Tuhan mampu memelihara kehidupan ialah mengingatkan manusia akan segala yang baik. Jemaat haruslah memahami dengan benar bahwa Allah sanggup memelihara, menolong manusia dengan janji-Nya.

Menurut hemat penulis, langkah praktis yang jemaat harus terapkan ialah membuka hati dan memberikan pikiran untuk senantiasa diperlengkapi oleh pemahaman firman Tuhan. Jemaat haruslah percaya bahwa firman-Nya berkuasa memelihara kehidupan jemaat. Jemaat haruslah sedia hati untuk mempelajari, meneladani para tokoh Alkitab ${ }^{13}$ bagaimana mereka berjuang berjumpa dengan firman-Nya, sehingga hal tersebut akan memperlengkapi konsep berpikir jemaat. Sehingga saat jemaat percaya bahwa firman Allah memberikan pemeliharaan hidup, jemaat akan senantiasa mencintai Tuhan dan segala ketetapannya. Allah dapat memelihara kehidupan umat dengan cara apa saja, termasuk melalui firman Tuhan.

\section{Allah Berkuasa Memberikan Keselamatan}

Berdasarkan wawancara, sejatinya jemaat belumlah memahami bahwa Allah yang memberikan firman adalah Allah yang berkuasa memberikan keselamatan. ${ }^{14}$

${ }^{10}$ Paul Enns, The Moody Handbook of Theology 1, (Malang: Literatur SAAT, 2004), 185

${ }^{11}$ Yakub B. Susabda, Mengenal dan Bergaul Dengan Allah, (Yogyakarta: Yayasan Andi, 2010), 104.

${ }^{12}$ Oleh firman-Nya segala sesuatu telah dijadikan dan firman itu dinyatakan di dalam diri Tuhan Yesus Kristus.Firman-Nya berkuasa menyelamatkan jiwa dan mengubah hidup manusia menjadi lebih baik. Ibrani 1: 3

${ }^{13}$ Musa, dalam mengemban tugas Allah dalam memimpin Bangsa Israel untuk memasuki tanah Perjanjian mengalami banyak tantangan. Dalam keadaan tersebut Allah senantiasa berfirman kepada Musa, Allah memberikan jalan keluar, kekuatan, penghiburan kepadanya dan menyatakan mujizat bahkan pemeliharaan-Nya baginya dan Bangsa Israel.Ketika Musa dan umat Allah berjalan dalam ketaatan firman-Nya, mereka aka nada pemeliharaan Allah dan penjagaan Allah. Bilangan 14: 1-22

${ }^{14} \mathrm{EP}$, (Nama Inisial), 05 Juli 2018 
John Perkins menuliskan, "Allah adalah Allah seluruh umat manusia yang mampu memberikan keselamatan." 15 Berdasarkan uraian penulis pada Bab II menjelaskan bahwaKeselamatan yang Allah berikan dalam konteks raja Daud ialah memberikan kemenangan, perlindungan, kekuatan, pengharapan dan menyelamatkan Daud dari rancangan jahat orang-orang jahat. Artinya Allah berkuasa memberikan keselamatan kepada semua orang di dalam segala keadaan.

Maka gereja haruslah melengkapi jemaat dengan pemahaman-pemahaman siapa Allah di dalam Alkitab. Demikian halnya dengan jemaat haruslah memperlengkapi diri dengan pengetahuan-pengetahuan Alkitab tanpa harus selalu bergantung dengan pelayan Tuhan. Gereja perlu mengadakan Kebaktian Kebangunan Rohani (KKR) untuk membakar semangat rohani jemaat sehingga mereka percaya kepada Yesus sebagai penyelamat hidup. Kebaktian tersebut dilakukan dengan sebuah harapan adanya penyegaran rohani.

Dalam pandangan penulis, gereja perlu memberikan pelayanan konseling atau pelayanan pribadi kepada setiap jemaat, dengan harapan gereja akan lebih memahami kondisi spiritual jemaat, sehingga jemaat akan mengalami pertumbuhan rohani. Artinya jemaat akan menyadari dan memiliki pengetahuan bahwa keselamatan hanya ada di dalam Yesus Kristus dan akhirnya jemaat mengalami kelahiran baru atau percaya kepada Yesus Kristus pemberi keselamatan.

\section{Firman Tuhan Memuat Dasar Hidup}

Jemaat haruslah memahami bahwa aturan dasar Allah sangat berpengaruh dalam mengubah semua orang. ${ }^{16}$ Dalam Mazmur 119: 97-106 menjelaskan bahwa alasan mendasar firman Tuhan mengandung segala aturan hidup bagi manusia ialah ke-Agungan firman Allah yang menyatakan sebuah intruksi hidup, kebenaran hidup, nasihat hidup.Kehidupan rohani (Spirituality of Christian Life) seseorang sangat bergantung pada firman-Nya. ${ }^{17}$ Dengan demikian jemaat perlu mengerti bahwa firman Tuhan memuat beberapa hal, diantaranya:

\section{Intruksi Bersumber Dari Allah Yang Mahakuasa}

Perintah Allah memberikan sebuah intruksi serta pemenuhan Allah bagi manusia. Perintah Allah mengacu kepada peraturan dan ketetapan Allah yang berkuasa bagi manusia. Perintah Tuhan memaparkan semua peraturan Allah. Sehingga sangat penting jemaat memahami bahwa di dalam firman-Nya Allah memberikan semua aturan hidup sebagai umat Allah. Ajith Fernando menuliskan bahwa "Tuhan berbicara kepada manusia melalui Alkitab."18

Menurut hemat penulis untuk sampai kepada tahap pemahaman bahwa firman Tuhan memberikan sebuah intruksi atau arahan, jemaat haruslah memiliki saat teduh setiap waktu seperti halnya raja Daud memiliki saat teduh untuk merenungkan firman Tuhan sepanjang hari. Jemaat perlu memiliki komitmen untuk senantiasa belajar

\footnotetext{
15 John Perkins, Penerapan Praktis Pola Hidup Kristen, (Surabaya: Gandum Mas, 1989), 625

${ }^{16}$ Charles Colson, Penerapan Praktis Pola Hidup Kriste, (Surabaya: Gandum Mas, 1989), 604

${ }^{17}$ Saumiman Saud, The Dynamic Life of Believers, (Jakarta: Yayasan Sinar Nusantara, 2004), 27

${ }^{18}$ Ajith Fernando, Pola Hidup Kristen, (Surabaya: Gandum Mas, 1989), 599
} 
firman-Nya secara intensif. Saat jemaat memiliki waktu khusus untuk belajar firmanNya, hal tersebut akan membawa jemaat kepada sebuah pemahaman bahwa firmanNya menyatakan sebuah petunjuk hidup atau intruksi.

\section{Firman Tuhan Memberikan Nasihat Hidup}

Allah menyatakan nasihat-Nya kepada manusia melalui kebenaran firman-Nya. ${ }^{19}$ Tujuan Allah memberikan nasihat agar umat berjalan berdasarkan kehendak-Nya. Nasihat Allah menunjukkan sebuah prinsip-prinsip yang dengannya manusia dapat berhubungan dengan Allah. Nasihat Allah senantiasa mendidik manusia, Allah mendidik umat-Nya berdasarkan peringatan-Nya.

Maka menurut hemat penulis langkah praktis yang perlu dilakukan oleh jemaat agar dapat memahami dengan baik bahwa firman-Nya memberikan sebuah nasihat ialah jemaat haruslah rutin mengikuti kegiatan pendalaman Alkitab dan seminar teologia. Dengan jemaat aktif mengikuti kegiatan tersebut, hal tersebut akan menyadarkan jemaat akan kekayaan firman-Nya dan menasehati jemaat terhadap ajaran-ajaran sesat yang sedang merusak gereja. Nasihat firman Allah akan menolong jemaat hidup di dalam perkenanan Allah, kekudusan, kesetiaan dan ketaatan. Saat jemaat jemaat hidup dalam nasihat firman Tuhan, jemaat akan senantiasa diingatkan oleh firman Tuhan. Mamfaat hidup dalam nasihat firman Tuhan ialah ada dalam pembinaan Allah.

Gereja haruslah berperan aktif di dalam membekali pengetahuan jemaat, sehingga menurut penulis seharusnya gereja bukanlah hanya sekedar tempat ibadah, akan tetapi gereja haruslah menjadi sebuah lembaga yang mendidik dan memuridkan jemaat. Maka dari itu gereja perlu menyediakan sebuah kegiatan yang sifatnya mengajarkan jemaat akan pengetahuan Alkitab, seperti halnya gereja perlu membuat program Kelompok Tumbuh Bersama (KTB) dimana di dalam kegiatan ini jemaat lebih banyak mempelajari secara bersaman akan firman Tuhan.

\section{Kebenaran Allah Merupakan Dasar Menjalani Hidup}

Allah adalah kebenaran yang sesungguhnya. ${ }^{20}$ Kebenaran Allah menuntun manusia berjalan pada jalan-Nya dan kekudusan-Nya.Allah dan firman-Nya adalah kebenaran yang tidak dapat dipisahkan. Firman-Nya merupakan penyataan diri Allahsebagai dasar kehidupan bagi setiap orang percaya. ${ }^{21}$ Tanpa kebenaran Allah manusia hanya akan berjalan di dalam kekeliruan, kekacauan dan cenderung hidup di dalam dosa.

Menurut hemat penulis geraja haruslah menyediakan kegerakan untuk membawa jemaat kepada sebuah pemahaman bahwa firman-Nya menyatakan segala kebenaran. Kegerakan tersebut ialah menyediakan sebuah program pembekalan bagi jemaat seperti diakannya Sekolah Alkitab Malam (SAM) dan upaya-upaya yang memotivasi jemaat untuk belajar firman-Nya. Sehingga hal tersebut akan melahirkan

19 Edwin Louis, Pemenang Bukan Tidak Pernah Gagal, Bukan Tidak Pernah Menyerah, (Jakarta: Immanuel, 2002), 8

${ }^{20}$ Yohanes 14: 4-6

${ }^{21}$ Edwin Louis Cole, Menjadi Pria Sejati, (Jakarta: Metanoia, 2009), 345 
sebuah konsep berpikir kepada jemaat bahwa firman Tuhan adalah sebuah kebenaran mutlak yang memberikan petunjuk hidup sebagai umat Allah.

\section{Firman Allah Memberikan Pengajaran Hidup}

Pemberian hukum Taurat bertujuan untuk menolong manusia tetap dalam perkenanan Allah, menerangi akal budi, maupun untuk mengarahkan hidup manusia. ${ }^{22}$ Segala sesuatu yang Allah lakukan sesuai dengan pola dan berdasarkan suatu prinsipNya. ${ }^{23}$ Charles $\mathrm{H}$. Kraft menuliskan bahwa, "Firman yang tertulis memiliki kuasa dan kekuatan Ilahi yang memberikan pola hidup. ${ }^{24}$ Manusia yang berjalan berdasarkan pola-Nya senantiasa berada dalam perkenanan Allah. Umat Allah haruslah berlaku sesuai dengan ajaran Allah. ${ }^{25}$

Berdasarkan analisis penulis dalam landasan teori di bab II menegaskan bahwa Alkitab adalah sebuah buku yang memuat segala pengajaran hidup yang mampu mendidik manusia menjadi pribadi yang memiliki moralitas dan spiritualisme. Artinya Alkitab memberikan segala pengarajaran tentang hidup. Jemaat haruslah memahami bahwa firman Tuhan memberikan ajaran. Maka langkah praktis yang harus dilakukan oleh jemaat ialah menjadikan Alkitab sebagai referensi hidup, buku panduan hidup seperti halnya Daud menjadikan firman Allah sebagai referensi untuk menjalani hidup, dengan tetap melekat pada firman-Nya dan merenungkannya sepanjang hari.

\section{Firman Allah Memberikan Pengharapan}

Janji Allah adalah sebuah pengharapan yang memberikan kepastian hidup. Bagi raja Daud janji Allah lebih manis dari madu. ${ }^{26}$ Janji Allah mampu membuat Daud cinta kepada firman-Nya, sebab janji Allah memberikan pengharapan sejati. Janji Allah mampu menolong manusia untuk senantiasa hidup di dalam iman. Allah menyediakan pertolongan melalui diri-Nya dan firman-Nya. ${ }^{27}$

Maka menurut hemat peneliti sangatlah penting untuk dipahami oleh semua jemaat bahwa Alkitab adalah pemberian Allah yang memberikan sebuah kepastian dan pengharapan, seperti Daud percaya kepada semua janji Allah. Jemaat haruslah percaya kepada kuasa Alkitab yang selalu relevan.

${ }^{22}$ William Dyrness, Tema-Tema Dalam Teologi Perjanjian Lama (Malang; Gandum Mas, 2001), 109-

${ }^{23}$ Apabila kita mempelajari pola-pola-Nya dan mendasarkan iman kita pada prinsip-prinsip-Nya, maka hidup kita menjadi produktif. Tetapi jika kita hidup, berdasarkan personalitas, teori, dan keadaan lingkungan, maka hidup akan sembarangan, kacau dan dikendalikan oleh dosa. Edwin Louis, Pemenang Bukan Tidak Pernah Gagal, Bukan Tidak Pernah Menyerah,..., 59

${ }^{24}$ Charles H. Kraft, Berkomunikasi dengan Kuasa, (Malang: Gandum Mas, 2002), 124

${ }^{25}$ Di dalam hukum-hukum-Nya, Allah mengekspresikan sifat-sifat-Nya, juga memperingatkan manusia segala hal yang Allah kehendaki. Hukum Allah memberikan pola hidup suci dan pengabdian kepada Allah.Di dalam hukum-hukum Allah memuat segala peraturan-peraturan, undang-undang-Nya, sehingga Allah menghendaki manusia berjalan berdasarkan pola Allah yang tertulis dalam hukum-hukum-Nya.

${ }^{26}$ Mazmur 119: 103

${ }^{27}$ Edwin Louis Cole, Pemenang Bukan Tidak Pernah Gagal Tetapi Tidak Pernah Menyerah, (Jakarta: Immanuel, 2002), 116 


\section{Menjalani Hidup Sebagai Umat Allah Terletak Pada Cahaya Firman}

John Piper mengutip penyataan Edwards bahwa, "Firman Allah mengajarkan tentang realitas Ilahi yang mulia." ${ }^{28}$ Alkitab menyatakan bahwa cahaya Allah menuntun. Cahaya firman Allah memberikan kehidupan yang mampu membawa manusia kepada kebahagiaan. ${ }^{29}$ Cahaya firman memberikan penerangan, arah hidup, membuka pengertian terhadap kehendak Allah.

Menurut hemat penulis geraja haruslah menyediakan sebuah kegiatan-kegiatan rohani yang mendorong jemaat untuk menjadikan firman-Nya sebagai kebutuhan utama hidup. Gereja perlu menyediakan Ibadah Kebaktian Kebanguan Rohani (KKR), kegiatan Family Day (Fam Day) dalam setiap tahun atau beberapa waktu. Sehingga hal tersebut akan menolong jemaat untuk melihat bahwa firman-Nya adalah kebutuhan utama hidup. Jemaat haruslah mengalami Kristus setiap waktu dengan senantiasa berjumpa dengna firman-Nya.

\section{Firman-Nya Memberikan Intimasi}

Kebenaran firman Allah memberikan intimasi atau hubungan antara umat dan Allah. Sehingga jemaat haruslah memahami bahwa Alkitab dapat membangun relasi dengan Allah dan memberikan sebuah komunikasi yang intim, diantaranya:

\section{Firman-Nya Akan Membuat Kagum Kepada Allah}

Jemaat belum memahami bahwa firman Tuhan mampu membawa kepada suatu perasaan yang sangat kagum dan terpesona kepada Allah. ${ }^{30}$

Raja Daud menyadari betapa pentingnya pengajaran Allah yang tertulis di dalam Taurat Tuhan, sehingga Daud memelihara keintimannya dengan Allah melalui firmanNya. Merenungkan Taurat bukanlah sebuah paksaan, bukan sebuah kewajiban semata dan bukan pula beban, melainkan sebuah kesukaan yang didasari sebuah perasaan yang mendalam. ${ }^{31}$ Firman Tuhan akan membawa jemaat kepada suatu sikap dan kekaguman kepada Allah, seperti halnya Daud memiliki perasaan yang dalam kepada Allah, sehingga Daud dapat berkata bahwa hanya dekat Allah ada ketenangan.

Alasan mendasar firman Tuhan membuat semua manusia kagum oleh karena firman Tuhan memberikan sebuah kebenaran, kepastian, kekuatan yang mampu menghibur semua umat Tuhan. Memberikan petunjuk hidup yang menuntun kepada kehendak dan rancangan Allah yang mulia. Kuasa firman Tuhan yang mampu menuntu dengan setia dalam mengubah sikap hidup manusia. Allah senantiasa menggenapi

28 Firman Tuhan mampu memberikan terang dalam langkah-langkah kehidupan kita. Firman Tuhan berkuasa memperbarui hidup dan memberikan kekuatan baru di dalamnya. John Piper, Gairah Allah Bagi Kemuliaan-Nya, (Surabaya: Momentum, 2008), 11

${ }^{29}$ Mazmur 56: 13; 89: 15

${ }^{30}$ BP (Nama Inisial), 78-79

${ }^{31}$ Firman Tuhan membuat manusia lebih bijaksana. Firman Tuhan membuatnya lebih berakal budi.Daud menjadi lebih paham dari orang-orang tua yang bijaksana sekalipun.Memberikan kemampuan menahan diri dari segala godaan tindak kejahatan.Ada janji yang manis yang mampu memberikan penghiburan dikala susah.Mazmur 119: 93 
janji-Nya dalam setiap generasinya. ${ }^{32}$ Faedah firman Tuhan senantiasa membuat hati manusia selalu kagum dan terpesona kepada Allah.

Menurut hemat penulis gereja perlu membuat sebuah program yang membangun semangat rohani jemaat. Gereja perlu menerapkan kegiatan persekutuan pagi di gereja setiap harinya. Gembala bersama Majelis perlu mengadakan kunjungan kepada setiap keluarga, di dalam perkunjungan tersebut gembala membina jemaat jemaat untuk senantiasa membangun komunikasi kepada Tuhan.

\section{Memberikan Komunikasi Yang Intensif}

Komunikasi Daud kepada Allah tampak pada aktivitasnya yang senantiasa merenungkan Taurat Tuhan. Dalam keadaan yang sangat sulit sekalipun Daud tetap berkomunikasi kepada Allah melalui firman-Nya. ${ }^{33}$ Firman Tuhan membuat raja Daud melekat kepada Allah dengan cara menyediakan waktu untuk berkomunikasi kepada Allah melalui firman-Nya. Daud senantiasa berkomunikasi kepada Allah dengan merenungkan Taurat. ${ }^{34}$

Intimasi Daud terlihat dari sebuah keputusan-keputusan yang tidak menyimpang dari kebenaran Allah. Keputusan yang Daud ambil senantiasa berdasarkan konfirmasi dari Allah. ${ }^{35}$ Allah berkomunikasi kepada Daud dengan Allah memberikan hikmat kepada Daud untuk menghadapi orang-orang fasik. Ketika Allah berfirman hal tersebut merupakan salah satu bentuk komunikasi Allah kepada manusia.

Maka langkah praktis yang perlu dilakukan jemaat ialah menyediakan waktu untuk membaca firman-Nya dengan membuat sebuah agenda bacaan setiap harinya. Gereja perlu menyediakan pembekalan kepada jemaat tentang kuasa firman Tuhan di dalam aspek kehidupan rohani. Jemaat haruslah memahami bahwa firman Tuhan adalah sarana yang paling tepat untuk berkomunikasi kepada Allah bukan hanya melalui doa dan penyembahan.

\section{Firman-Nya Akan Mendorong Seorang Untuk Menjadi Setia dan Taat}

Intimasi hidup yang dimiliki raja Daud terhadap Taurat Tuhan melahirkan sebuah kesetiaan untuk senantiasa berpegang kepada hukum-hukum Tuhan. Firman Tuhan mengajarkan sebuah ketaatan hidup. Kesetiaan dan ketaatan yang dimiliki raja Daud merupakan sebuah akibat seorang yang merenungkan Tuarat-Nya. Firman Tuhan senantiasa menuntun hidup umat agar mampu berjalan di dalam ketaatan.

Menurut hemat penulis, gereja haruslah menyediakan sebuah kelompokkelompok pada setiap jemaat untuk melakukan pembinaan yang di dalamnya ada sebuah sharing seperti hal nya pemuridan. Maka setelah gereja membuat sebuah kegiatan tersebut akan terus mendorong jemaat untuk setia dan taat kepada hukumhukum-Nya dan belajar mempelajari kebenaran firman Tuhan dengan baik.

${ }^{32}$ I Samuel 6: 10, 15

${ }^{33}$ Mazmur 119: 42a , 51, 54

34 Hanya sekedar memikirkan atau mempertimbangkan akan tetapi lebih mengarah kepada kesediaan untuk mempelajari setiap waktu, secara mendalam serta mengamati karya Allah secara mendalam, sedia memandang pada Allah secara sungguh-sungguh. Merenungkan dengan seluruh perhatian terhadap firman-Nya

${ }^{35}$ I Samuel 18: 12-14 


\section{Firman-Nya Akan Melatih Hidup}

Kata "mengajar" dalam Bahasa Ibrani ynlt") rEAh (hayarah) yaitu taugh. ${ }^{36}$ Allah membentuk dan menuntun kehidupan umat-Nya dengan membimbing mereka berdasarkan firman-Nya. Daud menyadari bahwa Allah melatih hidup, karakternya dengan memberikan pengajaran melalui hukum-hukum-Nya. Kata kunci untuk memahami penyebab raja Daud memiliki sebuah tekad untuk tidak menyimpang dari hukum-hukum Tuhan ialah Allah yang memberikan pengajaran kepada Daud melalui firman-Nya.

\section{Firman Tuhan Membentuk Karakter}

Firman Allah memiliki daya yang diperlukan dalam pembentukan watak dan karakter. ${ }^{37}$ Tujuan Allah memberikan firman-Nya ialah agar umat-Nya memiliki sikap hidup yang sesuai dengan cerminan umat Allah. Allah membentuk karakter Daud dengan firman-Nya. Karakter hidup sebagai umat Allah mampu membuat jemaat menjaga, memelihara, menguasai diri dan menjauhkan diri dari dosa.

Menurut hemat penulis, gereja perlu membuat sebuah buku refleksi yang mengisahkan para tokoh Alkitab, dimana firman Allah menjadi sebuah sentral dalam pembentukan karakter hidup tokoh-tokoh Alkitab. Sehingga jemaat memiliki sebuah buku panduan yang mendorong jemaat memahami cerita para tokoh Alkitab dan akhirnya memotivasi jemaat untuk membaca firman Tuhan.

Jemaat perlu menyadari bahwa kebenaran firman Tuhan memiliki kuasa dan kekuatan di dalam membentuk karakter manusia. Jemaat perlu memahami bahwa firman tersebut menerangi akal budi manusia, setia kepada hukum-hukum Tuhan, membenci segala jalan dusta, beroleh pengertian dan membuat manusia cinta kepada kebenaran Allah. Dalam bagian ini jemaat perlu memahami bahwa firman Tuhan:

\section{Memberi Kekuatan Untuk Menahan Kaki Dari Kejahatan}

Arti menahan kaki ialah menahan, menguasai dirinya terhadap hal-hal yang bertentangan dengan segala hukum-hukum Tuhan. Daud memelihara hidupnya dari perbuatan dosa oleh karena Taurat Allah senantiasa mengingatkannya. Taurat Allah memampukan Daud tidak melakukan segala perbuatan yang melanggar hukumhukum Allah dan yang meluakai hati Tuhan.

Dengan demikian, langkah utama yang perlu dilakukan oleh jemaat ialah menghidupi firman Tuhan di dalam kehidupan sehari-hari. Jemaat perlu memberikan hati untuk senantiasa diingatkan, dievaluasi oleh kebenaran firman Tuhan dan jemaat perlu merelakan hati untuk Allah menata hidup dan membentuk hidup di dalam segala keadaan. Kerelaan untuk bersedia belajar firman Tuhan adalah hal prinsip yang harus dilakukan oleh jemaat.

\section{Firman-Nya Membuat Umat Menjadi Benci Segala Jalan Dusta}

${ }^{36}$ Istilah taugh diterjemahkan teach yaitu mengajar, melatih, menghajar. John M. Echols dan Hassan Shadily, Kamus Inggris-Indonesia, (Jakarta: PT Gramedia Pustaka Utama, 1976) 580

37 Y. Tomatala, Penatalayanan Gereja yang Efektif di Dunia Modern, (Malang: Gandum Mas, 2001), 42 
Sebagian jemaat mudah menyimpang dari kebenaran. Jemaat terlalu sering mengabaikan firman Tuhan oleh karena keinginan daging dengan menyimpang dari kebenaran Allah.

Daud memiliki kesetiaan dan ketaatan terhadap Taurat-Nya. Kesetiaan membuatnya memiliki komitmen untuk tidak melupakan dan meninggalkan hukumhukum Tuhan. Sikap hidup tersebut senantiasa membuat Daud melakukan kebenaran. Hukum-hukum Allah mengajar untuk menimbang segala hal berdasarkan ketentuanketentuan Allah. Hukum Allah memberikan pengetahuan hidup sebagai umat Allah.

Dalam pandangan penulis gereja perlu menyediakan sebuah materi-materi pendalamam Alkitab yang membahas tentang akibat seorang yang setia kepada firman-Nya dan akibat hidup seorang yang hidup di dalam dosa. Kemudian jemaat haruslah memahami perintah firman Tuhan, supaya jemaat memiliki sikap hidup yang sesuai dengan kebenaran firman-Nya.

\section{Firman-Nya Menjadikan Seorang Bijaksana dan Berakal Budi}

Allah memberikan hikmat dan kebijaksanaan kepada Daud oleh karena Daud bersedia memelihara dan melakukan firman Tuhan. Akibat seorang yang bergaul dengan firman-Nya ialah hidup bijaksana dan berakal budi. Orang yang bijaksana adalah seorang yang memiliki kearifan. Setiap orang yang dikuasai, dikomandoi oleh perintah-Nya akan memperoleh hikmat. Hanya perintah Tuhan yang mampu membuat manusia menjadi lebih bijaksana dan berakal budi. Kebijaksanaan menolong manusia mampu menempatkan diri di dalam segala keadaan.

\section{KESIMPULAN}

Alktitab adalah firman Allah (The Bible Contains TheWord of God) yang diilhami Allah. ${ }^{38}$ Alkitab memuat semua perkataan dan suatu kekuatan untuk memberi kelahiran baru, memberi keselamatan, memberi anugerah, membangun iman, mengahasilkan iman. ${ }^{39}$ Gereja perlu menyediakan perpustakaan di gereja, diskusi kelompok pendalaman Alkitab (PA), KTB (Kelompok Tumbuh Bersama) dan Komsel. Komsel adalah salah satu cara mengajarkan jemaat menjadi seorang pribadi takut akan Tuhan dalam pemahaman akan firman Tuhan. ${ }^{40}$

Dengan demikian, kebenaran Mazmur 119: 97-106 sungguh sangatlah relevan. Firman Tuhan relevan oleh karena: Pertama, Pemberi firman Tuhan adalah Allah yang berkuasa memelihara kehidupan dan memberi keselamatan. Kedua, Firman memuat

${ }^{38}$ Alex Abraham Tanusaputra, Salvation Keselamatan, (Bethany: Scholl Of Ministry, tth), 4

${ }^{39}$ I Petrus 1: 23; Roma 1: 16; Kisah Para Rasul 20: 24; Roma 10: 17

${ }^{40}$ Pelayanan Komsel menolong jemaat mempelajari Firman Tuhan. Dengan demikian jemaat akan lebih mengenal Allah. Suasana Komsel akan menolong setiap jemaat untuk dapat menikmati pemahaman firman Tuhan, belajar dan mulai mengenal Allah. Jemaat akan mulai membangun hubungan pribadi dengan Tuhan secara bertanggung jawab. Tidak hanya itu saja pelayanan Komsel bertujuan menjangkau para jemaat, menolong mereka mengerti apa yang dikatakan Alkitab. Ruth F. Selan, Pembinaan Warga Jemaat, (Bandung: Kalam Hidup, 2000), 76 
segala aturan hidup manusia. Ketiga, Firman Tuhan memberikan intimasi hidup antara umat dan Allah. Keempat, Firman Tuhan membentuk karakter hidup manusia.

\section{KEPUSTAKAAN}

Josh Mc Dowell dan Don Stewart, Jawaban bagi pertanyaan orang yang belum percaya, (Malang: Gandum Mas, tth), 13 John Joseph Owens, Analytical Key to the Old Testament Vol 3 Ezra-Song Og Salomon, 480

Kenneth Barker, The NIV Study Bible New International Version, 919 Lockman Foudation, New American Standard Bible, (Califirnia: J. B. McCabe Company,1977), 875

R. Laird Harris, Gleason L. Archer and Bruce K. Waltke, Theological Wordbook Of

The Old Testament, (Chicago: The Moody Bible Institute, 1980), 948

Keluaran 25-30; Keluaran 36-39; Imamat 8 Jhon M. Echols dan Hassan Shadily, Kamus Inggris-Indonesia, (Jakarta: PT Gramedia, 1982), 276

Paul Enns, The Moody Handbook of Theology 1, (Malang: Literatur SAAT, 2004), 185 Yakub B. Susabda, Mengenal dan Bergaul Dengan Allah, (Yogyakarta: Yayasan Andi, 2010), 104.

John Perkins, Penerapan Praktis Pola Hidup Kristen, (Surabaya: Gandum Mas, 1989), 625

Charles Colson, Penerapan Praktis Pola Hidup Kriste, (Surabaya: Gandum Mas, 1989), 604

Saumiman Saud, The Dynamic Life of Believers, (Jakarta: Yayasan Sinar Nusantara, 2004), 27

Ajith Fernando, Pola Hidup Kristen, (Surabaya: Gandum Mas, 1989), 599

Edwin Louis, Pemenang Bukan Tidak Pernah Gagal, Bukan Tidak Pernah Menyerah, (Jakarta: Immanuel, 2002), 8

Edwin Louis Cole, Menjadi Pria Sejati, (Jakarta: Metanoia, 2009), 345

William Dyrness, Tema-Tema Dalam Teologi Perjanjian Lama (Malang; Gandum Mas, 2001), 109-111

Edwin Louis, Pemenang Bukan Tidak Pernah Gagal, Bukan Tidak Pernah Menyerah, ..., 59

Charles H. Kraft, Berkomunikasi dengan Kuasa, (Malang: Gandum Mas, 2002), 124 John Piper, Gairah Allah Bagi Kemuliaan-Nya, (Surabaya: Momentum, 2008), 11

M. Echols dan Hassan Shadily, Kamus Inggris-Indonesia, (Jakarta: PT Gramedia Pustaka Utama, 1976) 580

Y. Tomatala, Penatalayanan Gereja yang Efektif di Dunia Modern, (Malang: Gandum Mas, 2001), 42

Alex Abraham Tanusaputra, Salvation Keselamatan, (Bethany: Scholl Of Ministry, tth), 4

1I Petrus 1: 23; Roma 1: 16; Kisah Para Rasul 20: 24; Roma 10: 17

Ruth F. Selan, Pembinaan Warga Jemaat, (Bandung: Kalam Hidup, 2000), 76 